\title{
Diastolic Dysfunction and Its Implications to Serum Magnesium Changes in Hypertensives
}

\section{Ekwere Ifeoma Toyin, Naiho Alexander Obidike, Ojieh Emeka Anthony, Odigie Mike Osagie, Ohwin Peggy Ejiro}

College of Health Sciences, Delta State University, Abraka, Nigeria

Email address:

osgiedeprof@yahoo.com (O. M. Osagie)

${ }^{*}$ Corresponding author

To cite this article:

Ekwere Ifeoma Toyin, Naiho Alexander Obidike, Ojieh Emeka Anthony, Odigie Mike Osagie, Ohwin Peggy Ejiro. Diastolic Dysfunction and Its Implications to Serum Magnesium Changes in Hypertensives. Advances in Applied Physiology. Vol. 4, No. 1, 2019, pp. 5-10.

doi: 10.11648/j.aap.20190401.12

Received: May 20, 2019; Accepted: June 24, 2019; Published: July 13, 2019

\begin{abstract}
Overtime, Diastolic dysfunction (DD), which is seen in damping blood, and pressure build up within the ventricles has been associated with different disease states including chronic hypertension, coronary heart disease, aging, aortic stenosis, hypertrophic and restrictive cardiomyopathies. Diagnosis is by echocardiography (ECG) and often cumbersome. Howbeit, in acute stages of hypertension, prolongation of ventricular activation time in an ECG session has been described as potential marker for diagnosing DD. Current study was therefore undertaken to investigate ventricular activation time in essentially hypertensive Nigerians. One hundred and sixty two (162) hypertensives were recruited for the study. Their compliance to antihypertensive medication, blood pressure control, and electrocardiographic changes were determined and measured. Venous blood sample was then drawn and placed in special tubes to determine the serum magnesium concentrations, using a standard Colorimetric assay machine, Using the statistical measure of association (correlation), correlation between serum magnesium and ECG parameters was calculated using the Pearson's correlation coefficient. One way analysis of variance (ANOVA) was also explored in obtaining differences in mean between variables. From our observations, only a weak correlation was found between serum magnesium levels and ECG findings across the study population. This proved statistically insignificant at $\mathrm{p}<0.05$. Other factors such as antihypertensive medications, duration of blood pressure and the control of blood pressure did not show any significant relationship.
\end{abstract}

Keywords: Diastolic Dysfunction, Magnesium, Hypertension

\section{Introduction}

\subsection{Background}

Diastolic dysfunction results when the diastole part of the pumping action of the ventricles is abnormal [1]. The ventricles do not properly relax and become stiff thus they cannot fill with blood properly. This causes damping blood, as blood from the next heartbeat tries to enter the ventricles, pressure in the ventricles increases; leading to extra pressure and fluid build-up in the pulmonary vessels (i.e. pulmonary congestion) or in the vessels that lead back to the heart (i.e. systemic congestion) [2]. The condition impedes oxygenation of blood in the lungs, resulting in shortness of breath and mortalities. Systemic congestion due to Diastolic dysfunction also has detrimental effects on other organs e.g. the kidney and liver, as a result of poor organ perfusion. Swelling and congestion may also occur in the legs and within the abdomen.

The main cause of diastolic dysfunction are chronic hypertension, coronary heart disease, aging, aortic stenosis, hypertrophic cardiomyopathy and restrictive cardiomyopathy. Diastolic dysfunction initially does not cause any symptoms $[1,2]$ However, it could progressively affect other organs causing diastolic heart failure. Diastolic dysfunction is difficult to diagnose. Diagnosis is usually by echocardiography, which enables assessment of diastolic relaxation and ventricular stiffness and thickening. However prolongation of the ventricular activation time in an ECG change has been described as a potential marker for diastolic dysfunction (DD) in early hypertension. In our centre, 
echocardiography is not routinely done for all patients with essential hypertension and the ventricular activation time in persons with essentially hypertension has not been extensively studied in our centre.

In patients with Left Ventricular Hypertrophy (LVH), abnormalities in both myocardial relaxation and passive filling have been reported [3]. Myocardial relaxation, which reflects the time course and extent of cross bridge dissociation after systolic contraction is reportedly modified by the load imposed on the muscle, the rapid reduction of cytosolic calcium to basal level, and those factors such as intracellular $\mathrm{pH}$ that modify myofilament sensitivity to calcium [3]. In older patients with isolated systolic hypertension, concentric LVH is common.

Magnesium deficiency has been implicated in the pathogenesis of hypertension with epidemiological and experimental studies demonstrating an inverse correlation between blood pressure and serum magnesium levels [4]. Experimental studies have also linked hypomagnesaemia with the development of vascular dysfunction, and atherosclerosis. A relationship has also been reported between the rennin-angiotensin system, magnesium, and blood pressure. Hypertensive patients with high renin activity have been reported to have significantly lower serum magnesium levels than normotensive subjects, also plasma renin activity was found to be inversely associated with serum magnesium [5]. Diastolic dysfunction, including the presence of a Doppler filling pattern of impaired relaxation, has been observed in $>80 \%$ of older hypertensives [6]. Diastolic dysfunction initially does not cause any symptoms. However, it could progressively affect other organs causing diastolic heart failure [7]. Diastolic dysfunction is difficult to diagnose. Diagnosis is usually by echocardiography, which enables assessment of diastolic relaxation and ventricular stiffness and thickening $[7,8]$.

\subsection{Aim of Study}

This study aimed at determining the implications of serum magnesium changes to diastolic dysfunction in adult hypertensive humans. Specifically, study determined ECG changes in hypertensives, and investigated the relationship between selected ECG parameters and serum magnesium levels.

\section{Materials and Methods}

\subsection{Study Design}

Study was a descriptive, cross sectional type of experimental design.

\subsection{Study Area}

The study was carried out at the University of Benin Teaching Hospital (UBTH), Benin City, Edo State, Nigeria. UBTH is a tertiary healthcare institution in Edo state, southern Nigeria that provides specialized care for a large proportion of patients in Edo, Delta, and neighbouring states alike.

\subsection{Study Population}

Population for this study was drawn from the community of hypertensive adults who monthly attends the Consultant Out-patient Clinic (COPD) for treatment.

\subsection{Inclusion Criteria}

Selection of subjects for participation in the study was based on their diagnosis with essential hypertension. Such participants were aged between 30 and 65 years, and must regularly seek care at the COPD unit of the UBTH; and who gave their informed consent for participation in the study.

\subsection{Exclusion Criteria}

Subjects with hypertrophic cardiomyopathy, restrictive cardiomyopathy and/or cardiomyopathy from other known sources, who had been diagnosed to have coronary heart disease, aortic stenosis, and similar cardiovascular ailments, were exempted from the study.

\subsection{Sample and Sampling Technique}

Sample size for the study was drawn from aforementioned population. Mathematically, this was determined using the relation below [9];

$$
\mathrm{n}=\frac{Z \alpha / 2) 2 \sigma 2}{d 2}
$$

Where $\mathrm{Z} \alpha=$ standard normal deviate at $95 \%$ confidence interval $=1.96$

$\sigma=$ standard deviation of the characteristic of interest in the target population

$$
\mathrm{d}=\text { the margin of error }=0.05
$$

Substituting the values in the above formula, the sample size $n$ was calculated as

$$
n=\frac{1.96 \times 1.96 \times 0.12 \times 0.12}{0,02 \times 0.02}=138.29=139
$$

To make up for attrition, $10 \%$ of the sample size was added to make up for non-responses which was $13.83=14=$ 153.

However a total of 162 participants were eligible and thus selected for this study.

\subsection{Procedure}

\subsubsection{Ethical Clearance}

After approval by the Research and Bioethics Committee of the Department of Human Physiology, Delta State University Abraka, Ethical clearance was also obtained from the Ethics and Research Committee of the University of Benin Teaching Hospital (UBTH), in Benin, Edo State, Nigeria. Written informed consent was obtained from two hundred and six participants who were recruited using a simple random sampling procedure. 


\subsubsection{Data Collection}

By way of blind balloting, a structured questionnaire was used for data collection. Socio demographic data of participants was taken and recorded. With the individual barefoot in neutral position of a Mechanical Weighing and Height Scale (RGZ-160, Manufactured by Shanghai Maney Medical Technology Company, Limited, 2015), Subjects' weights were measured in kilogram. Patient's heights were also measured in meters using the attached standiometer with the patient standing on the firm, wide, flat base. This was done using the moveable horizontal headboard placed in contact with the most superior part of the head of the patient free of head gears. Participant's BMI was calculated using; Weight $(\mathrm{kg}) /$ Height $(\mathrm{m})^{2}$. The following interpretations were made from the calculated BMI: $<18.5 \mathrm{~kg} / \mathrm{m}^{2}$-underweight; 18.5 to $24.9 \mathrm{~kg} / \mathrm{m}^{2}$-normal weight; 25.0 to $29.9 \mathrm{~kg} / \mathrm{m}^{2}$ - over weight; 30.0 to $39.9 \mathrm{~kg} / \mathrm{m}^{2}$-obese; 40.0 to $49.9 \mathrm{~kg} / \mathrm{m}^{2}$ morbid obesity; $>50 \mathrm{~kg} / \mathrm{m}^{2}$-super obesity.

\subsection{Determination of Serum Magnesium $\left(\mathrm{Mg}^{2+}\right)$ Concentrations}

\subsubsection{Principle}

$\mathrm{Mg}^{2+}$ is precipitated as magnesium ammonium phosphate, with subsequent estimation of the phosphate by the molybdenum blue method.

Serum magnesium $\left(\mathrm{Mg}^{2+}\right)$ levels were determined by the Molybdenum Blue-Briggs method. The above principle was employed with modifications for phosphate determination described by Touyz (1999). In any case, the magnesium component was estimated by the yellow color produced upon addition of vanadate and molybdate to the precipitate, just after removing any present $\mathrm{Ca}^{2+}$.

To achieve this, venous blood sample was drawn from participants and placed in special tubes to determine the serum magnesium concentrations measured using a standard Colorimetric assay machine (Abbott 1000 SR, manufactured by Graham Abbott, United States of America, 2007). Using the same equipment, the serum calcium and phosphate levels were measured and recorded. Also other electrolytes (sodium, potassium, chloride and bicarbonate) and urea levels were recorded. The following were regarded as normal values: serum magnesium $1.7-2.4 \mathrm{mg}$. $\mathrm{dL}^{-1}$; serum calcium $8.0-10.5 \mathrm{mg}$. dL ${ }^{-1 ;}$ serum phosphate $2.0-5.5 \mathrm{mg}^{-\mathrm{dL}^{-1}}$ serum sodium 135 - 145 mmol.L ${ }^{-1 ;}$ serum potassium $3.5-$ $5.0 \mathrm{mmol} . \mathrm{L}^{-1}$; serum chloride 96 to $106 \mathrm{mmol}^{-\mathrm{L}^{-1}}{ }^{-1}$ s serum bicarbonate $20-30 \mathrm{mmol} . \mathrm{L}^{-1}$; urea $10-50 \mathrm{mmol} . \mathrm{L}^{-1}$.

\subsubsection{Electrocardiogram (ECG) Readings}

A 12-lead ECG was done using an electrocardiograph machine (AK 12, 12-Channel ECG Machine; Manufactured by Carl Novel, Germany, 2012). The machine was set to record at the rate of $25 \mathrm{~mm}$ per second and the electrocardiogram printed out. The readings from the electrocardiogram were noted, measured and recorded. The following parameters were recorded as normal values; normal heart rate- 60 to 100 beats per minute. $\mathrm{P}$ wave duration 0.08 to $<0.12$ seconds, $\mathrm{P}$ wave height $<2.5 \mathrm{~mm}$; QRS complex duration not $>0.1$ or 0.12 seconds; $\mathrm{T}$ wave duration 0.1 to 0.27 seconds and $\mathrm{Q}$ wave size not $>1 \mathrm{~mm}$ in height and not $>0.04$ seconds in duration. Normal R wave height- more than $8 \mathrm{~mm}$ but less than $30 \mathrm{~mm}$; normal duration of PR interval- 0.12 to 0.2 seconds; normal duration of QT interval- 0.2 to 0.44 seconds; normal ST segment duration 0.08 to $<0.15$ seconds with the $\mathrm{J}$ point not higher than $1 \mathrm{~mm}$ above the isoelectric line.

\subsection{Data Analysis}

Using the Statistical Package for Social Sciences (SPSS) Version 20, statistical measures of central tendencies (Mean) was conducted on obtained data, presenting as means \pm standard deviation. Significance level was set at $\mathrm{p}<0.05$ while $95 \%$ confidence interval was constructed around estimates.

\section{Results}

One hundred and sixty two patients completed the study. There were 45 males (27.8\%) and 117 females $(72.2 \%)$. The mean age was 53.87 ( 8.786 ) years (age range 28 to 65 years).

Table 1. Clinical Characteristics of Respondents.

\begin{tabular}{lllll}
\hline Variable & Mean & SD ( \pm ) & Minimum & Maximum \\
\hline $\begin{array}{l}\text { Supine } \\
\text { Pulse rate (b/min) }\end{array}$ & 78 & 12.0 & 54 & 110 \\
$\begin{array}{l}\text { Diastolic Blood Pressure } \\
\text { (mmHg) }\end{array}$ & 88.2 & 13.7 & 60 & 162 \\
$\begin{array}{l}\text { Systolic Blood Pressure } \\
\text { (mmHg) }\end{array}$ & 136.9 & 20.4 & 96 & 210 \\
$\begin{array}{l}\text { Mean Arterial Blood } \\
\text { Pressure (mmHg) }\end{array}$ & 104.4 & 14.6 & 75.3 & 177.3 \\
$\begin{array}{l}\text { Erect } \\
\text { Diastolic Blood Pressure } \\
\text { (mmHg) }\end{array}$ & 85.3 & 14.2 & 55 & 149 \\
$\begin{array}{l}\text { Systolic Blood Pressure } \\
\text { (mmHg) }\end{array}$ & 134.9 & 21.3 & 93 & 200 \\
$\begin{array}{l}\text { Mean Arterial Blood } \\
\text { Pressure (mmHg) }\end{array}$ & 101.8 & 15.4 & 70.3 & 165 \\
\hline
\end{tabular}

Table 2. Percentage ECG Changes in Hypertensives.

\begin{tabular}{lll}
\hline ECG Findings & Frequency & Percent \\
\hline Normal & 20 & 12.3 \\
Abnormal & 142 & 87.7 \\
Total & 162 & 100.0 \\
\hline
\end{tabular}

As shown from above table, $12.3 \%$ of the respondents had normal ECG while a majority $n=142(87.7 \%)$ had abnormal ECG.

Table 3. Average Duration of Respondents' ECG Waves.

\begin{tabular}{lll}
\hline Variables & Mean & SD $( \pm)$ \\
\hline Heart Rate (beats per minute) & 81.41 & 16.37 \\
Duration of P Wave (seconds) & 0.107 & 0.022 \\
Duration of PR Interval (seconds) & 0.170 & 0.037 \\
Duration of Q Wave (seconds) & 0.003 & 0.016 \\
Duration of QRS complex (seconds) & 0.064 & 0.022 \\
Duration of ST Segment (seconds) & 0.138 & 0.043 \\
Duration of T Wave (seconds) & 0.148 & 0.042 \\
Length of Sin V1+ R in V5 (seconds) & 27.91 & 10.26 \\
Length of S wave in V1 (seconds) & 12.90 & 7.16 \\
VAT in V1 (seconds) & 0.008 & 0.013 \\
VAT in V5 (seconds) & 0.016 & 0.010 \\
VAT in V6 (seconds) & 0.018 & 0.010 \\
\hline
\end{tabular}


Table 4. Percentage Serum Magnesium Levels of Respondents.

\begin{tabular}{lll}
\hline Serum Magnesium Levels* & Frequency & Percent \\
\hline Low (Hypomagnesaemia) & 14 & 8.6 \\
Normal & 139 & 85.8 \\
High (Hypermagnesaemia) & 9 & 5.6 \\
Total & 162 & 100.0 \\
\hline
\end{tabular}

*Normal serum magnesium $1.7-2.4 \mathrm{mg}$. $\mathrm{dL}^{-1}$.

Above table shows the serum magnesium levels of respondents in this study$8.6 \%(\mathrm{n}=14)$ had abnormally low magnesium levels, 5.6\% $(\mathrm{n}=9)$ had hypermagnesaemia while a majority $(85.8 \% ; \mathrm{n}=139)$ of adults with essential hypertension had normal serum magnesium levels. The mean serum magnesium was $1.95( \pm 0.28) \mathrm{mg} \cdot \mathrm{dL}^{-1}$ the range was $1.69 \mathrm{mg} . \mathrm{dL}^{-1}$ (minimum $1.01 \mathrm{mg} . \mathrm{dL}^{-1}$ and maximum $2.70 \mathrm{mg} \cdot \mathrm{dL}^{-1}$ )

Table 5. Correlation between Respondents' Serum Magnesium Levels and ECG Changes.

\begin{tabular}{llll}
\hline & Correlationcoefficient, $\mathbf{r}$ & p value & $\begin{array}{l}\text { Level of } \\
\text { Significance }\end{array}$ \\
\hline Eerum Magnesium & $\begin{array}{l}\text { ECG Changes } \\
-0.128\end{array}$ & 0.105 & NS \\
\hline
\end{tabular}

Correlation is significant at 0.05 level (2-tailed) $(\mathrm{n}=162)$ NS (Not Significant)

Result from above table shows there is a weak negative relationship between the serum magnesium levels and the ECG changes. This was not significant $(\mathrm{p}=0.105)$.

Table 6. Correlation of Respondents' Serum Magnesium Levels with Specific ECG Parameters.

\begin{tabular}{llll}
\hline & $\begin{array}{l}\text { Correlation } \\
\text { coefficient, } \mathbf{r}\end{array}$ & $\begin{array}{l}\text { p } \\
\text { value }\end{array}$ & $\begin{array}{l}\text { Level of } \\
\text { Significance }\end{array}$ \\
\hline Serum Magnesium & $\begin{array}{l}\text { P wave Duration } \\
0.095\end{array}$ & 0.228 & NS \\
& Q wave Duration & & \\
& -0.112 & 0.157 & NS \\
& QRS Duration & & \\
& 0.073 & 0.354 & NS \\
& ST Segment Duration & & \\
& 0.145 & 0.066 & NS \\
& QT Interval Duration & & \\
& -0.005 & 0.946 & NS \\
& PR Interval Duration & & \\
& 0.023 & 0.77 & NS \\
& & \\
& -0.034 & 0.626 & NS \\
RVH & & \\
& -0.214 & 0.006 & S \\
VAT & & \\
-0.092 & 0.246 & NS \\
\hline
\end{tabular}

Correlation was significant at $\mathrm{p}<0.05$ level (2-tailed) $(\mathrm{n}=162)(\mathrm{NS}-\mathrm{Not}$ Significant; S - Significant)

Above table shows a weak negative relationship between serum magnesium levels and Q wave duration, duration of QT- interval, LVH and VAT of hypertensive patients. These were not statistically significant. There was a negative relationship between serum magnesium levels and RVH which was statistically significant.

\section{Discussion}

Prolongation of the VAT has been associated with DD in patients with newly diagnosed untreated hypertension [11]. The ventricular activation time (VAT) is the time it takes for the ventricle to depolarise. It can be calculated from a standard 12-lead electrocardiogram (ECG). We can estimate it by noting the time from the onset of the QRS to the sudden down stroke of the QRS. The sudden down stroke is called the intrinsic deflection. In the right oriented leads, a normal VAT is $0.02 \mathrm{~s}$ and on the left e.g. V6 the duration should not exceed $0.04 \mathrm{~s}$.

From this study, it is seen that there was a weak negative relationship between serum magnesium levels and ECG findings across the study population. As serum magnesium levels decrease, there is increase in abnormality seen with the some of the ECG findings. This was however not statistically significant. There was also a weak negative relationship between serum magnesium levels and Q wave duration, the duration of the QT interval, left ventricular hypertrophy, right ventricular hypertrophy and ventricular activation time. While a statistically significant negative relationship was noted between serum magnesium levels and right ventricular hypertrophy, the relationship between serum magnesium levels and the other ECG parameters were not statistically significant. Factors such as adherence to drug therapy, blood pressure control, and age were the significant factors related to ECG findings among the respondents to this study.

In patients with LVH, abnormalities in both myocardial relaxation and passive filling have been detected. Myocardial relaxation, which reflects the time course and extent of cross bridge dissociation after systolic contraction, is modified by the load imposed on the muscle, the rapid reduction of cytosolic calcium to basal level, and those factors such as intracellular $\mathrm{pH}$ that modify myofilament sensitivity to calcium [3]. In older patients with isolated systolic hypertension, concentric LVH is common. Diastolic dysfunction, including the presence of a Doppler filling pattern of impaired relaxation, has been observed in $>80 \%$ of older hypertensives [3].

In this study, the incidence of hypomagnesemia among this sample was low $(8.5 \%)$ suggesting magnesium deficiency. Hypermagnesaemia was recorded in $15.2 \%$ of the patients while a larger majority (77.3\%) had normal magnesium levels. This finding in this study was similar to that by Muzasti and Lubis (2015) in which low serum magnesium was recorded by in $10.7 \%$ of hypertensive patients [11]. Other studies have shown varying results of serum magnesium in Nigerian patients. Odusan et al. reported an incidence of $32.4 \%$ in diabetic patient while a higher of hypomagnesaemia $36 \%$ and $93.8 \%$ has been recorded in some studies among pregnant women $[12,13]$. The latter may be as a result of the higher metabolic rate seen in this group of individuals.

Magnesium is one of the major intracellular cations. A normal concentration of magnesium is required for normal neuromuscular activity. Intracellular magnesium is an important cofactor for various enzymes, transporters, and nucleic acids that are essential for normal cellular function, replication, and energy metabolism. Up to fifty percent of the $25 \mathrm{~g}$ (1000 mmol) of total body magnesium resides in bone, whereas almost all of extra skeletal magnesium is located inside the cells [13]. It is known physiologically that although serum magnesium levels may not accurately reflect 
the level of total body magnesium since only $1 \%$ of body magnesium is found in the extracellular fluid, it is a very good estimation of the intracellular magnesium. Thirty to forty percent of dietary magnesium $(140-360 \mathrm{mg} / \mathrm{d})$ is absorbed, mainly in the jejunum and ileum. Its absorption is stimulated by $1,25(\mathrm{OH})_{2}$ D. It is excreted in the urine and its serum concentration is regulated by renal magnesium reabsorption. Approximately $60 \%$ of magnesium is reabsorbed in the cortical thick ascending limb of loop of Henle cTAL, $20 \%$ is reabsorbed in the proximal tubule, and $5-10 \%$ in the distal convoluted tubule [13]. Parathyroid hormone increases magnesium reabsorption in the cTAL, whereas hypercalcemia and hypermagnesemia inhibit magnesium reabsorption.

Hypomagnesemia is usually defined as serum magnesium $<0.7 \mathrm{mmol} / \mathrm{L}, 1.4 \mathrm{mEq} / \mathrm{L}$, or $1.7 \mathrm{mg} / \mathrm{dl}$. Hypomagnesemia has been found to have a prevalence of up to $15 \%$ in the general population and up to $65 \%$ in patients in the intensive care units [15]. Magnesium (Mg) deficiency has been found to correlate with a higher mortality and worse clinical outcome, particularly in critical care patients [15]. Magnesium has been directly implicated in hypocalcemia, tetany, hypokalemia, and arrhythmias [13]. It has been reported that magnesium may play a role in stroke, ischemic heart disease, and bronchial asthma. In addition an increased incidence of urinary stone disease is found in patients with dietary magnesium deficiency. In this study, the patients with hypomagnesaemia did not manifest overt additional symptoms. However it is advisable that patients with hypomagnesemia receive magnesium replacement since this is correlated with adverse pathophysiological consequences. In this study, there was also a low incidence of hypermagnesemia. Although, hypermagnesemia is only a prognostic marker in patients with congestive heart failure, none of the patients in this study had congestive cardiac failure and were excluded from the study. Also from this study, a weak negative correlation is observed between serum magnesium levels and ECG variables across the study population. This was however statistically insignificant. Other factors such as duration of blood pressure and the control of blood pressure also did not show any significant relationship with serum magnesium levels.

Generally, the association between serum magnesium and blood pressure have yielded conflicting results. Older studies [16-18], found a positive association between serum magnesium and blood pressure in hypertensive patients studied. On the other hand, the relation between serum magnesium and blood pressure was evaluated in recent studies and showed no association was identified between serum magnesium and systolic blood pressure and the development of cardiovascular complications [19]. Similarly, results from different studies showed no evidence of an association between serum magnesium and blood pressure [20, 21].

This study demonstrated a high incidence of hypertensive heart disease from the ECG findings especially left ventricular hypertrophy. Hypertension is a disease characterized by end-organ complications, leading to high morbidity and mortality in many cases. People with untreated or uncontrolled hypertension often run the risk of developing complications directly associated with the disease [22]. Left ventricular hypertrophy (LVH) has been shown to be a significant risk factor for adverse outcomes both in patients with hypertension and in the general population. Oluseyi and Adeyemi (2018) showed that the ECG LVH with strain was significantly associated with higher LV internal dimensions and volumes, but insignificantly associated with lower Ejection fractions in Nigerian hypertensives [23]. Left ventricular hypertrophy (LVH) in hypertension is associated with severe cardiovascular risk and poor prognosis, particularly in the black race.

\section{Conclusion}

Hypomagnesemia is usually defined as serum magnesium less than $0.7 \mathrm{mmol} / \mathrm{L}, 1.4 \mathrm{mEq} / \mathrm{L}$, or $1.7 \mathrm{mg} / \mathrm{dL}$ [15]. Observed from this study was a relatively low serum magnesium level, suggesting magnesium deficiency in participants. Hypermagnesaemia was recorded in $5.6 \%$ of sampled subjects while a larger majority (85.8\%) had normal magnesium levels. Current study also showed a weak negative correlation between serum magnesium levels and ECG findings across the study population which was however not statistically significant. Thus, a poor correlation exists between serum magnesium levels and ECG changes of hypertensives.

\section{References}

[1] Ganong WF (2005). Blood as a circulatory Fluid \& the Dynamics of Blood \& Lymph Flow. A Review of Medical Physiology. McGraw Hill, Boston. $22^{\text {nd }}$ ed. 521-553.

[2] Guyton, A. C. and Hall, J. E. (2006). Overview of the Circulation; Medical Physics of Pressure, Flow, and Resistance. Elsevier, philadephia. $11^{\text {th }}$ ed. 832-839.

[3] Lorell BH, Carabello BA (2000). Left Ventricular Hypertrophy-Pathogenesis, Detection, and Prognosis. Circulation; 102:470-479.

[4] Sontia B, Touyz RM (2007). Role of magnesium in hypertension. Achieves of Biochemistry and Biophysics; 458 (1): 33-39.

[5] Cunha A. R, Umbelino B, Correia ML, Neves MF (2012). Magnesium and Vascular Changes in Hypertension. International Journal of Hypertension; 1-7.

[6] Lanier GM, Vaishnava P, Kosmas CE, Wagman G, Hiensch R, Vittorio TJ (2012). An update on diastolic dysfunction. Cardiology in Review; 20 (5): 230- 236.

[7] Nagueh SF, Smiseth OA, Appleton CP, Byrd BF, Dokainish $\mathrm{H}$, Edvardsen T (2016). Recommendations for the evaluation of left ventricular diastolic function by echocardiography: An update from the American society of echocardiography and the European association of cardiovascular imaging. European Heart Journal - Cardiovascular Imaging; 17 (12): 1321-1360. 
[8] Singh AS, Masuku MB (2014). Sampling Techniques and Determination of Sample Size in Applied Statistics Research: An Overview. International Journal of Economics, Commerce and Management; 2 (11): 1-22.

[9] Touyz RM, Milne FJ (1999). Magnesium supplementation attenuates, but does not prevent, development of hypertension in spontaneously hypertensive rays. American Journal of Hypertension; 12 (8Pt 1): 757-65.

[10] Boles U, Almuntaser I, Brown A, Murphy RR, Mahmud A, Feely J (2010). Ventricular activation time as a marker for diastolic dysfunction in early hypertension. Am J. Hypertens; 23 (7): 781-5.

[11] Muzasti RA, Lubis HR (2015). Is blood magnesium level associated with total of antihypertensive drugs in chronic hemodialysis patient? Journal of Hypertension; 33: e28.

[12] Odusan OO, Familoni OB, Odewabi AO, Idowu AO, Adekolade AS. Patterns and Correlates of Serum Magnesium Levels in Subsets of Type 2 Diabetes Mellitus Patients in Nigeria. Indian Journal of Endocrinology and Metabolism. 2017; 21 (3): 439-442.

[13] Blaine J, Chonchol M, Levi M. Renal control of calcium, phosphate, and magnesium homeostasis. Clin J Am SocNephrol. 2015 Oct 7; 10 (10): 1886-7.

[14] Chobanian AV, Bakris GL, Black HR, et al. The Seventh Report of the Joint National Committee on Prevention, Detection, Evaluation, and Treatment of High Blood Pressure: the JNC 7 report. JAMA. 2003 May 21. 289 (19): 2560-72.

[15] Lameris AL, Monnens LA, Bindels RJ, Hoenderop JG (2012). Drug-induced alterations in $\mathrm{Mg} 2+$ homoeostasis. Clin Sci (Lond); 123 (1): 1-14.

[16] Meijs MF, Bots ML, Vonken E. (2007). "Rationale and design of the SMART Heart study: A prediction model for lelf ventricular hypertrophy in hypertension". Neth J. 15 (9): 295-8.
[17] Oladapo O. O, Salako L, Sadiq L, Shoyinka K, Adedapo K, Falase AO. Target-organ damage and cardiovascular complications in hypertensive Nigerian Yoruba adults: a cross-sectional study. Cardiovasc J Afr. 2012 Aug; 23 (7): 379-84.

[18] Adamu GU, Katibi AI, Opadijo GO, Omotoso AB, Araoye AM. Prevalence of left ventricular diastolic dysfunction in newly diagnosed Nigerians with systemic hypertension: a pulsed wave Doppler echocardiographic study. Afr Health Sci. 2010 Jun; 10 (2): 177-82.

[19] Khan AM, Sullivan L, PhD, McCabe E, Levy D, Vasan RS, Wang TJ. Lack of association between serum magnesium and the risks of hypertension and cardiovascular disease. Am Heart J. 2010 Oct; 160 (4): 715-720.

[20] Peacock JM, Folson AR, Arnett DK, Eckfelt JH, Szklo M (2011). Relationship of serum and dietary magnesium to incident hypertension: the Atherosclerosis Risk in Communities (ARIC) Study. Ann Epidemiol. Apr; 9 (3): 15965 .

[21] Song Y, Sesso HD, Manson JE (2006). Dietary magnesium intake and risk of incident hypertension among middle-aged and older US women in a 10-year follow-up study. Am J Cardiol; 98: 1616-21.

[22] Babatunde S L, Okechukwu OS, Adewole A A, Olulola OO (2009), Blood pressure control and left ventricular hypertrophy in hypertensive Nigerians annals of African medicine; 8: 156-162.

[23] Oluseyi A, Adewole A (2018). A comparative and correlation study of electrocardiographic and echocardiographic left ventricular parameters in hypertension. Annals of African Medicine; 15 (1) 33-40. 